\title{
SECTORIAL AND TECHNOLOGICAL GLOBAL INVESTMENT INTENTIONS, 2003 - 2016
}

\author{
Gílson Geraldino Silva Jr, UFSC, Brazil \\ José Maria F.J. Silveira, UNICAMP, Brazil \\ Henrique Reichert, FIESC, Brazil
}

dx.doi.org/10.18374/JIBE-19-3.6

\begin{abstract}
We analyzed greenfield-type Global Investment Intentions (GII) from 2003 to 2016, highlighting possible structural change due to the 2008 global economic crisis, sectorial and technologically. We use microdata panel regressions, mainly to check change impact effectiveness on Gll after 2008 global crisis and the results show that: i) all sectors had some intention to invest in the period 2003-2016, ii) before 2008 the electricity sector stands out, iii) after the global adverse shock Gll decreases, iv) by technological intensity in manufacturing before the shock the intentions turned to the sector of medium-high technology, then to low technological intensity after crisis, suggesting risk-averse behaviors and agents search for accommodation of the previous positions in their respective sectors. Both the approach and the research results are unpublished.
\end{abstract}

Keywords: Global Investment Intentions. The 2008 economic crisis. Panel data regression. 